Research Article

\title{
Morbidity pattern and its association with personal hygiene practices among school going children (11 to 15 years of age group) in Surendranagar, Gujarat, India
}

\author{
Komal P. Thekdi ${ }^{1}$, Girija P. Kartha ${ }^{1}$, Pukur I. Thekdi ${ }^{2}$
}

${ }^{1}$ Department of Community Medicine, C.U. Shah Medical College, Gujarat, India
${ }^{2}$ Department of General Surgery, C.U. Shah Medical College, Gujarat, India

Received: 06 June 2016

Accepted: 01 July 2016

*Correspondence:

Dr. Komal P. Thekdi,

E-mail: drkomalthekdi@gmail.com

Copyright: () the author(s), publisher and licensee Medip Academy. This is an open-access article distributed under the terms of the Creative Commons Attribution Non-Commercial License, which permits unrestricted non-commercial use, distribution, and reproduction in any medium, provided the original work is properly cited.

\section{ABSTRACT}

Background: The Millennium development goals have firmly established the issues of 'water, sanitation and hygiene on the global agenda. Public health importance of hand washing as well as its importance in reduction in some of the communicable diseases such as diarrhoea and acute respiratory infections (ARI) has been highlighted in many studies. Methods: A cross sectional study conducted in both private and government schools selected by simple random sampling. Each class had an enrolment of 50 students and all the students were interviewed through pre - tested questionnaire and clinical examination was done to find out health problems in a standardized way.

Results: There were 366 boys and 134 girls in the study population. The awareness regarding personal hygiene practices was maximum for daily bath $(84 \%)$; $49.8 \%$ of students had knowledge regarding health related problems and about $24.4 \%$ of children had health related problems.

Conclusions: Majority of the health problems affecting school children are preventable by promotion of hygiene practices through proper health education by the teachers who are the first contacts.

Keywords: Health problems, Morbidity, Personal hygiene, School children

\section{INTRODUCTION}

Poor hygiene practices and inadequate sanitary condition play major roles in the increased burden of communicable diseases in developing countries like India. Still a large proportion of the global morbidity and mortality is attributable to infectious diseases, e.g. they cause $62 \%{ }^{1}$

and $31 \%$ of all deaths in Africa and Southeast Asia, respectively. $^{2}$ It is well-documented that children with proper hand-washing practices are less likely to report gastrointestinal and respiratory symptoms. ${ }^{3,4}$ Handwashing with soap can reduce diarrheal morbidity by $44 \%$ and respiratory infections by $23 \%$. $^{5,6}$
The Millennium development goals have firmly established the issues of "water, sanitation and hygiene on the global agenda. Public health importance of hand washing as well as its importance in reduction of communicable diseases such as diarrhoea and acute respiratory infections has been highlighted in many studies. The study was conducted with an objective to find out the awareness regarding personal hygiene practices, to assess the personal hygiene practices followed by the school children and its association with morbidity profile. An attempt was also made to assess the awareness regarding menarche and menstrual hygiene. 


\section{METHODS}

It was a cross sectional study. All schools were registered first and from the list one school from private and one school from government were selected for the study. school by simple random sampling. Students of $5^{\text {th }}$ to $9^{\text {th }}$ standards of the selected schools formed the study group. Prior permission was sought from the principal. School record was used for getting reasonable accuracy in age assessment. A pre-designed and pre-tested proforma was used for data collection. Clinical examination was done to assess the morbidities among school children.

\section{RESULTS}

Daily bathing (84\%), brushing teeth $(63 \%)$, washing hands with soaps and water were the most common hygienic practices in the school children (Table 1). Maximum personal hygiene practices not followed by the students were cutting nails $(40.8 \%)$; washing hands $(37.8 \%)$ followed by others (Figure 1$)$.

Out of 500 total students 134 girls were there; out of them 51 were aware regarding menstrual hygiene practices (Figure 2).

About $49.8 \%$ of the students had knowledge regarding common health problems in school children. Cold was the most common health problem they know (Table 2). Abdominal pain and worm infestations (6.0\%) were the most common health related problems sufferred by the children (Table 3).

A significant association found between personal hygiene practices followed by school children and their health related problems. $\left(\chi^{2}=65.2\right.$, d.f. $=1$, $\mathrm{P}$ value $\left.<0.001\right)$ (Table 4).

Table 1: Awareness regarding personal hygiene practices among school children $(\mathrm{n}=500)$.

\begin{tabular}{|lll|}
\hline Awareness regarding personal hygiene practices (N=500) & Yes & No \\
\hline Trim nails & $168(33.6 \%)$ & $332(66.4 \%)$ \\
\hline Wash hands with soaps & $267(53.4 \%)$ & $233(46.6 \%)$ \\
\hline Brush teeth & $315(63.0 \%)$ & $185(37.0 \%)$ \\
\hline Bath daily & $420(84.0 \%)$ & $080(16.0 \%)$ \\
\hline Wash hairs regularly & $135(27.0 \%)$ & $365(73.0 \%)$ \\
\hline
\end{tabular}

Table: 2 Knowledge of general health problems among both private and government school children $(\mathrm{n}=500)$.

\begin{tabular}{|ll|}
\hline Knowledge of general health problems & Frequency (percentage) \\
\hline Cold & $75(15.0 \%)$ \\
\hline Cough & $56(11.2 \%)$ \\
\hline Fever & $54(10.8 \%)$ \\
\hline Pain in abdomen & $18(03.6 \%)$ \\
\hline Headache & $26(05.2 \%)$ \\
\hline Backache & $12(02.4 \%)$ \\
\hline Toothache, earache etc. & $08(01.6 \%)$ \\
\hline Total & $249(49.8 \%)$ \\
\hline
\end{tabular}

Table: 3 Findings of health related problems of both government and private school children $(\mathrm{n}=500)$.

\begin{tabular}{|llll|}
\hline Health related problems & Private school & Government school & Total \\
\hline Dental problems & $10(2.0 \%)$ & $15(3.0 \%)$ & $25(5.0 \%)$ \\
\hline $\begin{array}{l}\text { Abdominal pain and worm } \\
\text { infestations }\end{array}$ & $09(1.8 \%)$ & $21(4.2 \%)$ & $30(6.0 \%)$ \\
\hline Ocular problems & $10(2.0 \%)$ & $16(3.2 \%)$ & $26(5.2 \%)$ \\
\hline Ear problems & $03(0.6 \%)$ & $06(1.2 \%)$ & $09(1.8 \%)$ \\
\hline Throat problems & $09(1.8 \%)$ & $15(3.0 \%)$ & $24(4.8 \%)$ \\
\hline Skin problems & $03(0.6 \%)$ & $05(1.0 \%)$ & $08(1.6 \%)$ \\
\hline Total (N=500) & $44(8.8 \%)$ & $78(15.6 \%)$ & $122(24.4 \%)$ \\
\hline
\end{tabular}


Table 4: Association of personal hygiene practices and health related problems $(n=500)$.

\begin{tabular}{|llll|}
\hline \multirow{2}{*}{ Following Personal hygiene practices } & \multicolumn{2}{l}{ Health related problems } & Total \\
\cline { 2 - 4 } & Yes & No & \\
\hline Yes & $36(12.3 \%)$ & $259(87.7 \%)$ & $295(59 \%)$ \\
\hline No & $86(41.9 \%)$ & $119(58.1 \%)$ & $205(41 \%)$ \\
\hline Total & 122 & 378 & $500(100 \%)$ \\
\hline
\end{tabular}

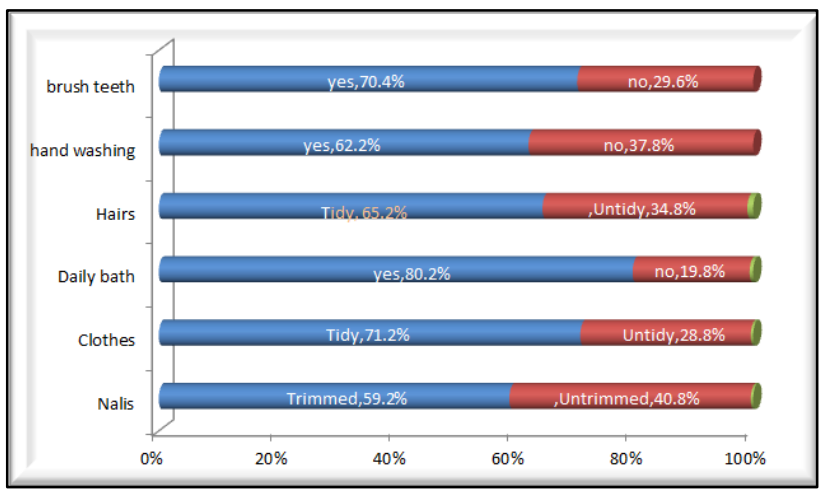

Figure 1: Personal hygiene practices followed by school children $(\mathbf{n}=500)$.

Study data revealed that maximum personal hygiene practices not followed by the students were cutting nails (40.8\%); washing hands $(37.8 \%)$ etc.

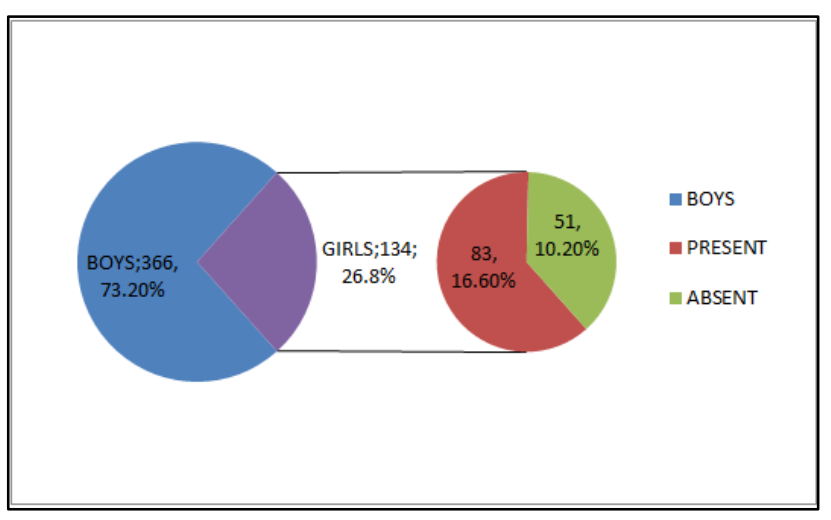

Figure 2: Awareness among girls regarding menstrual hygiene practices $(n=134)$.

\section{DISCUSSION}

Hygiene refers to practices associated with ensuring good health and cleanliness. School age children form a substantial proportion of the world's population, numbering about $24 \%$ of population of the developing world School setting provides a strategic point of entry for improving child health, self-esteem, life skills and behavior. Hygiene is very important for living a healthy life free from diseases. Poor hygiene practices and inadequate sanitary condition play major roles in the increased burden of communicable diseases within the developing countries.
Knowledge and awareness are some of the measures which are thought to be on the causal pathway to behaviour. The study revealed that proportion of positive hygiene behaviour among school children was fairly high in those who had adequate knowledge. In our study the maximum awareness regarding personal hygiene practices was daily bathing (84\%) followed by brushing teeth $(63 \%)$, washing hands with soaps $(53.4 \%)$ etc. there is a significant association found between personal hygiene practices followed by school children and their health related problems. $\left(\chi^{2}=65.2\right.$, d.f. $=1, \mathrm{P}$ value $\left.<0.001\right)$ The study carried out by Mulubirhan Assefa and Abera Kumie in which more than half of the children were aware on hand washing and water handling accounts for $58.9 \%$ and $52.7 \%$ respectively. ${ }^{1}$ Students who were aware reggarding personal hygiene practices in which $71.6 \%$ students followed positive hygiene behaviour as compared to those not aware had reported positive hygiene behaviour only $50.8 \%$ and the result was found statistically significant $(\mathrm{P}<0.001)$. Personal hygiene practices not followed by the students were untrimmed nails $(40.8 \%)$, unclean clothes $(37.8 \%)$, untidy hair (34.8\%), unclean teeth $(29.6 \%)$ etc. A study carried out by Kaviraj Motakpalli et al. in which $34 \%$ had bad oral hygiene followed by $25 \%$ unclean external or internal ear, $21 \%$ had unclean tongue, $14 \%$ had unclean nose, $11 \%$ had unclean skin, $8 \%$ had unclean clothes, $7 \%$ had uncombed and dirty hairs and $4 \%$ had unclean hands. ${ }^{7}$ Where as a study carried out by Paliwal in which dirty hairs $(17.9 \%)$, dirty clothes $(45.2 \%)$ dirty nails $(57.4 \%)$ were found which was nearly similar to our study. ${ }^{10}$ It was concluded that morbidities found amongst students are basically due to low awareness and negligent behaviour about personal hygiene which are the key areas of concern and by active involvement of school teachers and improvement in personal hygiene of school children, the reduction in related morbidities may be achieved. A holistic approach addressing social, economical and geographical characteristics of the children should be introduced aimed at improving the hygiene practices among school children. $49.8 \%$ of the students had knowledge regarding general health problems among both private and government school children $(\mathrm{N}=500)$. Out of them cold was the most common health problem narrated by them. Overall $122(24.4 \%)$ students suffered one or the other kind of health related problem. $(\mathrm{N}=500)$. In our study the most common morbidities were abdominal pain with worm infestation $(24.59 \%)$ followed by ocular problems $(21.31 \%)$, dental problems $(20.49 \%)$, throat pain $(19.67 \%)$, ear problems $(7.37 \%)$ and skin 
problems $(6.55 \%)$. out of the total health related problems. Ocular morbidities commonly found were refractory errors. Out of dental problems most common problems were staining of teeth, toothache and dental caries. The most common ear problems were itching, earache and wax impaction. The most common skin problems were itching and dryness of skin. In a study carried out in Karnataka; the major health related problems were dental problems (32.4\%), vitamin deficiency $(16.8 \%)$, skin diseases $(11 \%)$ respiratory tract infections $(9.2 \%)$, A study carried out by Mayavati S. Mhaske et al. in which the major morbidities observed were dental caries $(66.1 \%)$, upper respiratory tract infections (38.20\%), ear wax (29.9\%) and myopia $(10.0 \%)$ observed ENT problems (9\%), eye diseases $(8.2 \%)$, gastro intestinal $(7 \%)$ and others $(7.6 \%){ }^{7}$ Out of 295 students following personal hygiene practices in which only 36 students had health related problems whereas 205 students who were not following personal hygiene practices in which 86 students had health related problems a significant association found between personal hygiene practices followed by school children and their health related problems. $\left(\chi^{2}=65.2\right.$, d.f. $=1, \mathrm{P}$ value $<0.001)$.

\section{CONCLUSION}

Majority of the health problems affecting school children are preventable by promotion of hygiene practices through proper health education by the teachers who are the first contacts.

\section{ACKNOWLEDGEMENTS}

We are acknowledged to school principal; school teachers and the students who provide us a wonderful platform for carrying out this study and for their kind support.

Funding: No funding sources Conflict of interest: None declared

Ethical approval: The study was approved by the Institutional Ethics Committee

\section{REFERENCES}

1. Tamer GS, Erdogan S, Willke A. The frequency of the presence of intestinal parasites in students of arslanbey primary school. Turkiye Parazitol Derg. 2008;32:130-3.

2. Curtis VA, Danquah LO, Aunger RV. Planned, motivated and habitual hygiene behaviour: an eleven country review. Health Educ Res. 2009;24:655-73.

3. Ejemot RI, Ehiri JE, Meremikwu MM, Critchley JA. Hand washing for preventing diarrhoea. Cochrane Database Syst Rev. 2008:CD004265.

4. Snow M, White GL, Jr, Kim HS. Inexpensive and time-efficient hand hygiene interventions increase elementary school children's hand hygiene rates. J Sch Health. 2008;78:230-3.

5. Curtis V, Cairncross S. Effect of washing hands with soap on diarrhoea risk in the community: a systematic review. Lancet Infect Dis. 2003;3:27581.

6. Shrestha A, Narayan KC, Sharma R. Prevalence of intestinal parasitosis among school children in Baglung districts of Western Nepal. Kathmandu Univ Med J (KUMJ). 2012;10:3-6.

7. Motakpalli K, Indupalli AS, Sirwar SB. A study on health hygiene among school children in rural field practice area of ajims mangalore in Karnataka: india. International Journal of Bioassays. 2013;2(10):1407-10.

8. Assefa M, Kumie A. Assessment of factors influencing hygiene behaviour among school children in Mereb-Leke District, Northern Ethiopia: a cross-sectional study.BMC Public Health. 2014;14:1000.

9. Mhaske MS, Khismatrao DS, Kevin F, Pandve HT, Kundap RP. Morbidity pattern and personal hygiene in children among private primary school in urban area: are the trends changing? Journal of Family Medicine and Primary Care. 2013;2(3):266-9.

10. Vismita P, Paliwal CK, Nishi F, Chaturvedi S. Personal Hygiene Habits among School-Going Children in Rural Areas of Jaipur, Rajasthan, India. International Journal of Scientific Research and Reviews. 2014;3(2):126-42.

Cite this article as: Thekdi KP, Kartha GP, Thekdi PI. Morbidity pattern and its association with personal hygiene practices among school going children (11 to 15 years of age group) in Surendranagar, Gujarat, India. Int J Community Med Public Health 2016;3: 2125-8. 